We thank Miss J. B. Macdonald, S.R.N., for her help in the clinical observations, and all the volunteers who took part.

REFERENCES

Andrewes, C. H. (1948). J. roy. Soc. Arts, 96, 200.

Buckland, F. E., Bynoe, M. L., Philipson, L., and Tyrrell, D. A. J. (1959). J. Hyg. (Lond.), 57, 274.

Lennette, E. H., Fox, V. L., Schmidt, N. J., and Culver, J. O. (1958). Amer. J. Hyg., 68, 272.

Pereira, M. S., and Pereira, H. G. (1959). Lancet, 2, 539.

Pulvertaft, R. J. V., Davies, J. R., Weiss, L., and Wilkinson, J. H. (1959). j. Path. Bact., 77,19

Zitcer, E. M., Fogh, J., and Dunnebacke, T. H. (1955). Science, 122, 30 .

\section{DENTAL EXTRACTIONS IN PATIENTS WITH HEART DISEASE}

BY

\author{
H. McINTYRE, M.B., Ch.B., B.D.S., F.D.S. \\ Assistant Dental Surgeon, Manchester Royal Infirmary
}

The management of patients with heart disease requiring dental extractions is still the subject of considerable controversy. Opinions differ regarding the nature and duration of antibiotic cover, the permissible number of extractions at any one session, the choice of anaesthesia, and the need for in-patient as opposed to out-patient treatment.

Since the classical work of Okell and Elliott (1935) on the bacteriaemia induced by dental extractions, all workers are in agreement concerning the need for antibiotic cover. Penicillin still seems to be the antibiotic of choice, but opinions vary on the extent of the cover required. Thus the American Heart Association (1955) recommends the use of one injection pre-operatively on the day the teeth are removed, whereas Hobson and Juel-Jensen (1956) prefer to continue penicillin injections several days post-operatively.

Some practitioners believe that not more than one tooth should be removed at a visit, but a search of the literature has not revealed any evidence to support or disprove this contention. Hobson and Juel-Jensen (1956) and Archer (1956) recommend the admission to hospital of all patients with heart disease for dental extractions, but others do not stress the necessity for this.

As regards anaesthesia, the choice lies between general and local anaesthesia, with or without adrenaline. Mead (1951) considers that local analgesia is best and that adrenaline is not contraindicated; on the other hand, Comroe et al. (1954) advise local analgesia, but prefer to dispense with adrenaline. Feldman (1946) is of the opinion that no patient with heart disease need be denied the advantages of a general anaesthetic.

This paper describes the techniques in use in the dental department at the Manchester Royal Infirmary, and is based on the management of over 300 patients with heart disease. The latter were referred direct by the general practitioner or by the department of cardiology in the hospital.

Indications for Dental Treatment in Cardiac Patients

In general the indications for extraction are those used in routine dental practice. In patients with congenital lesions or rheumatic valvular disease, however, in order to lessen the risk of inducing a subacute bacterial endocarditis, extractions have often to be done where, in the normal subject, conservative therapy is the method of choice. Thus root-canal therapy is avoided in patients with apical infections; and, similarly, in patients with parodontal disease associated with mobility of the teeth, conservative parodontal therapy, necessitating frequent gum-massage, is not undertaken. A further indication for radical treatment is the presence of dental sepsis in patients suffering from subacute bacterial endocarditis. Finally, infected teeth are removed as a precautionary measure prior to cardiac surgery, preferably two to three weeks before the operation to allow adequate healing of the sockets.

\section{Management of Patient}

Preliminary Examination. - A careful dental examination is made in every case. The time so spent is used also to establish good rapport between the operator and the patient. A calm, methodical examination, conducted in a sympathetic manner, followed by a simple explanation of the procedures to be adopted, is usually sufficient to allay the fears of all but the most nervous patient. In the latter, phenobarbitone, 90-120 mg. orally four hours before extractions, or quinalbarbitone (" seconal "), 90-180 mg. orally one and a half hours before operation, is given to dispel apprehension. The newer "tranquillizers," such as meprobamate, do not appear to afford any advantage over the barbiturates. An additional advantage of the barbiturates is their ability to depress the sensitivity of the oral mucosa.

Antibiotic Therapy.-Patients with a history of rheumatic or congenital heart disease, or who gave a history of a previous attack of subacute bacterial endocarditis, were originally given 0.5 mega unit of soluble penicillin one hour pre-operatively, and the same dose was repeated two hours after extraction. Many patients failed to wait for the second injection, and so it was decided to give a single injection pre-operatively, consisting of soluble penicillin 0.5 mega unit plus procaine 0.3 mega unit. The lateral aspect of the thigh is the most convenient site for injection in dental patients. During the preliminary examination, inquiry is made regarding hypersensitivity to penicillin. Where such a history exists, the patient receives $500 \mathrm{mg}$. of tetracycline six-hourly for 12 hours before and after extraction.

Anticoagulant Therapy.-For obvious reasons this is discontinued two days prior to the extractions and is resumed the day after operation.

Anaesthesia.-Local anaesthesia is used in most patients and has been found to be very satisfactory. Its use is also convenient in a busy dental clinic. A solution of $2 \%$ lignocaine with $1 / 80,000$ adrenaline gives adequate anaesthesia. The total amount of the solution used in any one case varied from a minimum of $1.5 \mathrm{ml}$ to a maximum of $8 \mathrm{ml}$. Routine regional anaesthetic techniques, as determined by the teeth to be extracted, are used. The more sensitive regions of the mouth, such as the upper labial sulcus and the anterior region of the palate, have a surface application of a $5 \%$ lignocaine ointment, two or three minutes before the injection of the local anaesthetic. In addition, infiltration of the buccal and lingual mucosa over the appropriate teeth is carried out. It is essential that adequate time be allowed for anaesthesia to occur, and 
at least 10 minutes should elapse prior to upper-jaw extractions and 15 minutes prior to extractions in the lower jaw. General anaesthesia is not without risk in the cardiac patient. In my opinion general anaesthesia is required in the very young, in the uncooperative adult, and in the presence of acute infection. Where general anaesthesia is used, a specialist anaesthetist is engaged and the choice of anaesthetic agent and method of administration are left entirely to him.

Hospitalization.-Generally speaking, the ambulant cardiac patient who is physically capable of attending the dental clinic is regarded as suitable for out-patient treatment, irrespective of the nature of the heart lesion. The conditions which govern admission to hospital are : (a) patients requiring either in-patient investigation or treatment for their cardiac lesion; $(b)$ patients receiving anticoagulant therapy after myocardial infarction; and (c) patients in whom extractions are likely to be difficult -for example, those with impacted teeth or a previous history of difficult extractions. Multiple extractions, even a complete dental clearance, do not influence the decision regarding hospitalization.

Extractions.-Teeth are removed by standard procedures. After the extractions the mouth is cleaned with gauze pads, and the alveolar plates of the sockets are digitally compressed. Any remaining prominent processes of alveolar bone are removed with rongeur forceps. Where a tooth is fractured during its extraction, removal of the root is carried out with elevators, or by a surgical exposure. A gauze pad is placed over the sockets, and the patient is instructed to close the mouth, holding the pad in position for half an hour. If haemostasis is not achieved at the end of this time by means of pressure, sutures are employed. Mouth-washes are not advisable during the first 24 hours after operation, as their use in this period may interfere with normal haemostasis.

\section{Clinical Material}

During the past six years 313 patients were seen and treated in the department. In over $90 \%$ of these patients a careful follow-up was possible for a period of at least three months. It was felt that any complication or aggravation of the cardiac condition due to the dental treatment would be clinically obvious by the end of this period. No deliberate attempt was made, therefore, to observe the patients over a longer period, but in effect some $67 \%$ have been observed for periods varying from six months to six years.

In Table $I$ the series is classified according to age and the nature of the heart lesion. Space does not permit a fuller description of the clinical state, but in the Table an attempt has been made to indicate the frequency of those features of most importance in assessing clinical severity of the heart lesion. Under the heading "congenital heart disease " are included patients with Fallot's tetralogy, the Eisenmenger complex, tricuspid atresia, patent ductus arteriosus, and various septal defects. The group called " chronic valvular disease" comprises patients with an acquired valvular defect, either stenosis or incompetence. The valvular lesions in this group are mainly the sequelae of rheumatic carditis, and the commonest lesion is mitral stenosis. Four patients had aortic incompetence due to syphilis. Only one patient in cardiac failure due to pregnancy complicating chronic valvular disease was encountered, and she was not thought suitable for dental treatment.

Eighteen patients were seen who gave a past history of subacute bacterial endocarditis, associated with either a congenital heart lesion or rheumatic valvular disease. Eleven patients received dental treatment during an attack of subacute bacterial endocarditis.

The last group consists of patients with essential hypertension or with atheromatous disease of the coronary arteries. Those labelled coronary artery disease gave a history of one or more attacks of myocardial infarction.

\section{Observations and Incidence of Complications}

In the group as a whole the most striking feature from the dental aspect was the extent of the caries. These patients, when compared with a similar group of healthy people, appeared to have suffered much before seeking dental treatment. Thus it was by no means uncommon to encounter exposed pulps. As a result of this delay one saw many grossly infected mouths. Contrary to what might be expected, the incidence of congenital anomalies of the teeth in patients with cardiac lesions of developmental origin was no higher than in the general population. This clinical observation was confirmed in most patients by either radiological or histological examination, or both.

In patients with cyanosis due either to congenital heart disease or to congestive failure, and in patients with hypertension, excessive post-extraction haemorrhage was occasionally encountered. Such bleeding, except in one patient, was readily controlled by simple local measures such as digital compression of the gums or suture. The exception was a patient who had suffered from a mild degree of chronic congestive failure for about 18 months. This patient bled for 48 hours after the removal of two molar teeth. Investigation of his haemostatic process revealed a marked deficiency of factor VII and prothrombin, presumably due to liver damage as a result of the long-standing congestion of that organ. The haemorrhage was eventually controlled by the parenteral administration of vitamin $K_{1}$ and the local application of thrombin. An alarming prolonged haemorrhage was encountered in a child aged 8 years with Fallot's tetralogy. In this patient, in order to avoid the administration of two general anaesthetics, the removal of eight deciduous molars had been undertaken immediately prior to tonsillectomy. Slight oozing from the tonsillar beds resulted in continuous coughing, causing haemorrhage from the sockets. With haemorrhage occurring from both sources, it was difficult to treat either adequately, and before haemostasis was finally achieved a blood transfusion had to be given.

TABLe I.-Classification of 313 Patients with Heart Disease

\begin{tabular}{|c|c|c|c|c|c|c|c|c|c|c|}
\hline \multirow{2}{*}{\multicolumn{3}{|c|}{$\begin{array}{l}\text { Age } \\
\text { Group }\end{array}$}} & \multicolumn{2}{|c|}{ Congenital Heart Disease } & \multicolumn{3}{|c|}{ Chronic Valvular Disease } & \multicolumn{3}{|c|}{ Ischaemic Heart Disease } \\
\hline & & & Cyanotic & Non-cyanotic & Compensated & $\begin{array}{l}\text { Complicated } \\
\text { by Pregnancy }\end{array}$ & $\begin{array}{c}\text { In Congestive } \\
\text { Failure }\end{array}$ & $\begin{array}{c}\text { Coronary } \\
\text { Artery Disease }\end{array}$ & Hypertension & $\begin{array}{c}\text { Hypertension } \\
\text { with Angina }\end{array}$ \\
\hline $\begin{array}{l}\text { Children } \\
\text { Adults . }\end{array}$ & $\because$ & $\ldots$ & $\begin{array}{l}45 \\
20\end{array}$ & $\begin{array}{l}14 \\
13\end{array}$ & $\overline{148}$ & $\overline{15}$ & $\overline{13}$ & $\overline{20}$ & $\overline{18}$ & $\overline{7}$ \\
\hline
\end{tabular}


Despite the previously noted high incidence of sepsis the number of "dry sockets" seen was not excessive. Apart from the patients who developed "dry sockets," wound-healing was not delayed.

No case of sudden death in the chair occurred. One patient with the Eisenmenger complex died 10 hours after coming round from the anaesthetic. This was a child, aged 6 years, who had had cardiac catheterization performed prior to removal of the teeth, under the same anaesthetic.

In the first 24 hours after extraction no patient developed myocardial infarction.

Three patients with coronary artery disease died as a result of coronary thrombosis at intervals varying from two to four months after the extractions. It was felt that these deaths were not attributable to the dental operation.

One patient with hypertension developed paroxysmal tachycardia 48 hours after a dental clearance for gross sepsis. No other serious disturbance of the heart rhythm, such as fibrillation, gallop rhythm, etc., attributable to the dental treatment, was encountered in any other patient in the group. No paradoxical embolism followed dental extractions in the patients with congenital septal defects.

Subacute bacterial endocarditis did not develop within three months of the dental extractions in any patient. Occasionally in the presence of gross sepsis some patients showed a slight pyrexia up to $99^{\circ} \mathrm{F} .\left(37.2^{\circ} \mathrm{C}\right.$.) in the 24 hours after extractions. Unfortunately, routine postoperative blood cultures were not possible in all patients. In those in whom it was carried out the cultures remained sterile. The majority of patients in whom white-cell counts were carried out showed a slight transient rise in the polymorphonuclear count.

Eleven patients with dental sepsis were being treated for subacute bacterial endocarditis.

None of those patients who were pregnant suffered abortion or miscarriage within four weeks of the extractions.

\section{Discussion}

In the patient with heart disease no operative procedure is without danger. The risks involved are now well known and are to a certain degree dependent upon the nature of the heart lesion. For obvious reasons, any suggested method of management should combine the maximum protection against these risks with the minimum trouble to the dentist and discomfort to the patient. Elaborate schemes of antibiotic cover, compulsory admission to hospital, and difficult anaesthetic procedures are apt to break down under the stress in busy dental departments. It was decided, for these reasons, to simplify the procedure so far as was possible. The relative freedom from complications in the 313 patients treated justifies the simple technique adopted.

General anaesthesia, even in expert hands, has a slight but definite mortality rate, irrespective of the nature of the operation. The administration of a general anaesthetic to a cardiac patient should be carried out by a specialist anaesthetist under hospital conditions. The usual general anaesthetic procedure possible in dental practice often leads to some degree of anoxia, and this must be avoided at all costs in the patient with heart disease. In the co-operative patient general anaesthesia is not often necessary, and in this series it
TABLE II.-Relative Proportion of General to Local Anaesthesia in the Main Groups

\begin{tabular}{|c|c|c|c|}
\hline Anaesthetic & $\begin{array}{c}\text { Congenital } \\
\text { Heart } \\
\text { Disease }\end{array}$ & $\begin{array}{l}\text { Chronic } \\
\text { Valvular } \\
\text { Disease }\end{array}$ & $\begin{array}{c}\text { Ischaemic } \\
\text { Heart } \\
\text { Disease }\end{array}$ \\
\hline General $\left\{\begin{array}{l}\text { Adults } \\
\text { Children }\end{array}\right.$ & $\begin{array}{r}2 \\
45\end{array}$ & 1 & $\underline{2}$ \\
\hline Local $\left\{\begin{array}{l}\text { Adults .. } \\
\text { Children }\end{array}\right.$ & $\begin{array}{l}31 \\
14\end{array}$ & 175 & $\overline{43}$ \\
\hline
\end{tabular}

was almost entirely confined to the group of children with congenital heart disease (Table II).

It has been suggested that adrenaline should be avoided in the patient with heart disease for fear of inducing a cardiac arrhythmia or collapse. It will be appreciated that local anaesthesia induced with adrenaline-free solutions is not as intense or prolonged as with solutions containing adrenaline. Thus in some of the earlier patients in the series it was found that the use of adrenaline-free anaesthetic solutions resulted in the extractions being completed under suboptimal anaesthesia. It was felt that the alarm induced by pain, no matter how slight, was a potential danger in these patients. Only one patient developed paroxysmal tachycardia, and the use of adrenaline in the localanaesthetic solution might possibly have been responsible. The dangers attendant on the use of adrenaline are perhaps more theoretical than actual in the concentration employed.

TABLE III.-Treatment of Main Groups

\begin{tabular}{lc|c|c}
\hline & $\begin{array}{c}\text { Single } \\
\text { Extraction }\end{array}$ & $\begin{array}{c}\text { Multiple } \\
\text { Extractions }\end{array}$ \\
\hline $\begin{array}{l}\text { Congenital heart disease } \ldots \\
\text { Valvular disease (with rheumatism) }\end{array}$ &.. & 37 & 85 \\
\hline
\end{tabular}

Table III shows the number of single and multiple extractions carried out. Up to eight teeth were removed at one session. It can be appreciated from the Table and from the low incidence of undesirable sequelae in the series as a whole, that multiple extractions are as safe in the patient with heart disease as in the healthy patient. There is nothing in the results to support the view held by some practitioners that one tooth at a time should be removed. Each single extraction is an ordeal for the cardiac patient, and it is felt that such a protracted procedure is unnecessary, as multiple extractions in this series produced no more mental stress than the removal of one tooth.

In-patient Versus Out-patient Treatment.-With the criteria previously described, approximately $50 \%$ of the patients (Table IV) were considered fit for out-patient

TABLE IV.-Relative Proportion of Out-patient to In-patient Therapy in the Three Main Groups

\begin{tabular}{c|c|c|c|c}
\hline Type & $\begin{array}{c}\text { Congenital } \\
\text { Heart } \\
\text { Disease }\end{array}$ & $\begin{array}{c}\text { Chronic } \\
\text { Valvular } \\
\text { Disease }\end{array}$ & $\begin{array}{c}\text { Ischaemic and } \\
\text { Hypertensive } \\
\text { Heart Disease }\end{array}$ & Totals \\
\hline $\begin{array}{ccc}\text { Out-patient } \\
\text { In-patient }\end{array}$ & $\begin{array}{cc}41 \\
\text { Totals }\end{array}$ & 51 & 85 & 20 \\
\hline & 92 & 176 & 45 & 156 \\
\hline
\end{tabular}

treatment. It can be seen from the Table that the number of out-patients as opposed to in-patients in each type of heart disease is about equal. The choice therefore depends on the clinical severity of the lesion rather than on its nature. 
Antibiotic Cover.-This is of the utmost importance for the patient with congenital or rheumatic heart disease. The method of administration for out-patients must be as simple as possible to avoid default by the patient. From the results recorded here a single combined injection of soluble and procaine penicillin appears adequate to prevent subacute bacterial endocarditis. Of the 11 patients with subacute bacterial endocarditis who received dental treatment, only two appeared to have become apyrexial as a result of the removal of dental sepsis. Nevertheless, it is very important that these patients should be examined dentally, and any teeth which are the seat of apical or parodontal infection should be removed. In subacute bacterial endocarditis adequate dental treatment should always be undertaken while the patient is still on full penicillin treatment. To leave infected teeth after recovery from subacute bacterial endocarditis invites a recurrence of the infection.

\section{Summary}

A simple technique for dealing with dental sepsis in the cardiac patient is described. It has been used, with few complications, in the treatment of 313 cases at the Manchester Royal Infirmary. Emphasis is laid on the simplicity of the procedure in order to encourage the cardiac patient to have dental treatment and to avoid disorganizing the routine in a busy dental clinic.

Many patients with advanced caries were treated. This was thought to be due to the patients' fear of the consequences of dental treatment on the heart lesion, or in some cases the medical adviser did not think the patient was fit to undergo dental extractions.

A simple technique is outlined. (1) Antibiotic cover is essential. One single pre-operative injection of soluble penicillin 0.5 mega unit plus procaine 0.3 mega unit is sufficient protection against the risk of subacute bacterial endocarditis. (2) $2 \%$ lignocaine with $1 / 80,000$ adrenaline is an effective anaesthetic. The use of adrenaline is not contraindicated. General anaesthesia is necessary in some cases and should be administered by a specialist anaesthetist under hospital conditions. (3) There is no limit to the number of extractions that can be done at any one treatment. In the series of 313 patients treated, no deterioration of the cardiac condition attributable to dental treatment occurred. This justifies the adoption of such a technique as outlined in dealing with dental sepsis in the cardiac patient.

I am grateful to Professor H. G. Radden and Dr. A. Morgan Jones for their encouragement and advice.

\section{REFERENCES}

American Heart Association (1955). J. Amer. med. Ass., 50, 328. Archer, W. H. (1956). Oral Surgery, 2nd ed., p. 2. Saunders, Philadelehia

Comroe, B. I., Collins, L. H., and Crane, M. P. (1954). Internal Medicine in Dental Practice, 4th ed., p. 96. Lea and Febiger, Philadelphia.

Feldman, M. H. (1946), Dent. Surv., 22, 1107.

Hobson, F. G., and Juel-Jensen, B. E. (1956). Brit. med. J., 2, 150

Mead, S. V. (1951). Anesthesia in Dental Surgery, 2nd ed., p. 39. Mosby, St. Louis.

Okell, C. C., and Elliott, S. D. (1935). Lancet, 2, 869.

The Empire Rheumatism Council booklet Rheumatic Fever: A Handbook for Parents, is available, free, to doctors only who may wish to pass it on to their patients' parents. Requests for the booklet should be made to the Council at Faraday House, 8-10, Charing Cross Road, London, W.C.2.

\section{PERIPHERAL NEUROPATHY IN THE " COLLAGEN DISEASES"}

\section{A CASE OF SCLERODERMA NEUROPATHY}

\author{
BY
}

\author{
R. F. KIBLER,* M.D. \\ AND
}

\section{F. CLIFFORD ROSE, $\dagger$ M.B., M.R.C.P. Lately Resident Medical Officer}

From the National Hospitals for Nervous Diseases, Queen Square, London

Peripheral neuropathy is well recognized as a frequent complication of polyarteritis nodosa. Lovshin and Kernohan (1948) found "clinically significant" neuropathy in 15 of the 29 cases verified at necropsy, an incidence of $52 \%$. The incidence among the other "collagen diseases," however, is much less.

Though Harvey et al. (1954) did not describe a single instance of peripheral neuropathy in their 138 cases of disseminated lupus erythematosus (D.L.E.), it is probably not as rare a complication as this would suggest. Heptinstall and Sowry (1952) and Scheinberg (1956) have each reported a case of D.L.E. verified at necropsy in which a symmetrical polyneuropathy was an early and significant feature of the disease. A clinically similar case was included in the report of Hart et al. (1957, Case 11). In a review of the neurological complications of 100 cases of D.L.E., Clark and Bailey (1954) stated that a polyneuropathy was a complication in three. Bailey et al. (1956) gave their experience in more detail. Five cases were reported, two with post-mortem examinations, in which either a symmetrical polyneuropathy (four cases) and/or a monoradiculitis multiplex (two cases) was a prominent manifestation. Scheinberg's estimate, therefore, of a 1 to $2 \%$ incidence of neuropathy in D.L.E. would not seem to be unreasonably high.

Characteristic perineural inflammatory nodules occur in a high proportion of patients with rheumatoid arthritis (Morrison et al., 1947), but peripheral neuropathy has been regarded as a rare manifestation. In recent years an increasing number of papers have appeared on the development of vascular lesions typical of polyarteritis nodosa in patients with rheumatoid arthritis; and though corticosteroid therapy may be responsible for this apparent increase (Smyth et al., 1959) such cases may occur quite independently of therapy (Ball, 1954). In many of these cases peripheral neuropathy has been an early and prominent manifestation of the arteritis (Ball, 1954 ; Sokoloff and Bunim, 1957 ; Kemper et al., 1957). Since the vascular lesion may differ from that seen in polyarteritis nodosa (Robinson et al., 1953; Rose, 1960), it remains controversial whether the arteritis is a feature of rheumatoid arthritis (Sokoloff and Bunim, 1957) or signifies polyarteritis nodosa complicating rheumatoid arthritis (Ball, 1954), so that the concept of a specific rheumatoid neuropathy remains in doubt. Hart et al. (1957) have considered the various aspects of this problem in their report of peripheral neuropathy in 10 cases of rheumatoid arthritis.

\footnotetext{
*Markle Scholar, at present at the University of Pittsburg.

$\dagger$ Now First Assistant, Neurological Department, St. George' Hospital, London.
} 